\title{
Experimental and kinetic study on ignition delay times of methane/hydrogen/oxygen/nitrogen mixtures by shock tube
}

\author{
ZHANG YingJia, HUANG ZuoHua*, WEI LiangJie \& NIU ShaoDong \\ State Key Laboratory of Multiphase Flow in Power Engineering, Xi'an Jiaotong University, Xi'an 710049, China
}

Received October 19, 2010; accepted June 14, 2011

\begin{abstract}
Ignition delay times of methane/hydrogen/oxygen/nitrogen mixtures with hydrogen amount-of-substance fractions ranging from 0-20\% were measured in a shock tube facility. The ambient temperature varied from 1422 to $1877 \mathrm{~K}$ and the pressure was maintained at 0.4 MPa behind the reflected shock wave. The experiments were conducted at an equivalence ratio of 2.0. The fuel mixtures were diluted with nitrogen gas so that the nitrogen amount-of-substance fraction was $95 \%$. The experimental ignition delay time of the $\mathrm{CH}_{4} / \mathrm{H}_{2}$ mixture decreased as the hydrogen amount-of-substance fraction increased. The enhancement of ignition by hydrogen addition was weak when the ambient temperature was $>1750 \mathrm{~K}$, and strong when the temperature was $<1725 \mathrm{~K}$. The ignition delay time of $20 \% \mathrm{H}_{2} / 80 \% \mathrm{CH}_{4}$ was only one-third that of $100 \% \mathrm{CH}_{4}$ at $1500 \mathrm{~K}$. A modified model based on GRI-Mech 3.0 was proposed and used to calculate the ignition delay times of test mixtures. The calculated results agreed with the experimental ignition delay times. Normalized sensitivity analysis showed that $\mathrm{HO} \cdot+\mathrm{H}_{2} \rightarrow \mathrm{H} \cdot+\mathrm{H}_{2} \mathrm{O}$ was the main reaction for the formation of the $\mathrm{H}^{\cdot}$ at $1400 \mathrm{~K}$. As the hydrogen amount-of-substance fraction increased, chain branching was enhanced through the reaction $\mathrm{H} \cdot+\mathrm{O}_{2} \rightarrow \mathrm{O} \cdot+\mathrm{HO} \cdot$, and this reduced the ignition delay time. At $1800 \mathrm{~K}$, the methyl radical $\left(\mathrm{H}_{3} \mathrm{C} \cdot\right)$ became the key species that influenced the ignition of the $\mathrm{CH}_{4} / \mathrm{H}_{2} / \mathrm{O}_{2} / \mathrm{N}_{2}$ mixtures, and sensitivity coefficients of the chain termination reaction $2 \mathrm{H}_{3} \mathrm{C} \cdot(+\mathrm{M}) \rightarrow \mathrm{C}_{2} \mathrm{H}_{6}(+\mathrm{M})$, and chain propagation reaction $\mathrm{HO}_{2}+\mathrm{H}_{3} \mathrm{C} \cdot \rightarrow \mathrm{HO}+\mathrm{CH}_{3} \mathrm{O}$ decreased, which reduced the influence of hydrogen addition on the ignition of the $\mathrm{CH}_{4} / \mathrm{H}_{2}$ mixtures.
\end{abstract}

shock tube, methane, hydrogen, chemical kinetics

Citation: Zhang Y J, Huang Z H, Wei L J, et al. Experimental and kinetic study on ignition delay times of methane/hydrogen/oxygen/nitrogen mixtures by shock tube. Chinese Sci Bull, 2011, 56: 2853-2861, doi: 10.1007/s11434-011-4635-4

Natural gas could be used in internal combustion engines and gas turbines [1,2], but its application has been limited because of unstable ignition and combustion. Experimental [3] and computational [4] studies have shown that addition of hydrogen to natural gas improves the tolerance of exhaust gas recirculation (EGR) and greatly reduces $\mathrm{NO}_{x}$ and hydrocarbon emissions, while maintaining the engine power. Therefore, from both economic and environmental viewpoints, addition of hydrogen to natural gas is effective. Experimental investigations on the fundamental combustion characteristics of methane/hydrogen mixtures have been carried out by several groups using different methods. Shrestha et al. [3] investigated the addition of relatively

*Corresponding author (email: Zhhuang@mail.xjtu.edu.cn) small amounts of hydrogen to methane in a spark ignition engine and showed that the performance and combustion were significantly enhanced, and emissions were reduced, which can be attributed to the fast and clean burning characteristics of methane with hydrogen. Shrestha et al. [3] thought analytical simulation of engine performance and suggested that the addition of hydrogen was considered through its production in situ on board the engine by electrolysis of water with the hydrogen by electrolysis was taken into account, the range of viable operation of such an engine was very narrow. Daguaut et al. [5,6] studied the kinetics of oxidation of hydrogen/natural gas mixtures on a fused silica jet stirred reactor at $1 \mathrm{MPa}$ from 900-1200 K with equivalence ratios of $0.3,0.6$, and 1.0. Their results showed that addition of hydrogen significantly increased the 
reactivity of the natural gas. The enhanced oxidation of methane by hydrogen could be attributed to increased production of the hydroxyl radical (HO-). Konnov et al. [7] conducted an experimental investigation of the adiabatic burning velocity of a methane/hydrogen/air flame using the heat flux method, and obtained the following empirical pressure correlation:

$$
S_{L}=S_{L 0} \exp \left(0.66\left(1-\left(p / p_{0}\right)^{0.57}\right)\right) .
$$

$\mathrm{Hu}$ et al. [8,9] conducted an experimental and numerical study on laminar burning characteristics of a premixed methane/hydrogen/air flame at room temperature and atmospheric pressure. They suggested that the unscratched laminar burning velocity increased with $\mathrm{H}_{2}$ addition, and the maximum unscratched laminar burning velocity shifted to the richer mixture side as the hydrogen amount-of-substance fraction increased.

As a fundamental characteristic parameter of fuel combustion, the ignition delay time is very important for describing autoignition, understanding the ignition mechanism, analyzing the chemical reaction pathway, and building, validating and improving kinetic models. Shock tube studies on ignition of methane/hydrogen/oxygen mixtures at high temperatures have been reported by Lifshitz et al. [10]. A promotion theory based on thermodynamics was proposed to account for the effect of hydrogen addition on ignition delay. Gersen et al. [11] investigated the autoignition behavior of methane/hydrogen mixtures containing hydrogen amount-of-substance fractions of $0-100 \%$ in a rapid compression machine. The ignition delay time was measured under stoichiometric conditions at 1.5-7.0 MPa and 950$1060 \mathrm{~K}$. Their results showed that the ignition delay times of the methane/hydrogen mixtures reduced as the hydrogen amount-of-substance fraction increased, and this effect was enhanced at higher temperatures and attenuated at higher pressures. Huang et al. [12] also found the ignition promotion effect was reduced at lower temperatures in their study of the ignition delay time of methane/hydrogen/air mixtures in a shock tube setup using engine relevant conditions at 1.6-4.0 MPa and 1000-1300 K. Cheng and Oppenheimer [13] conducted experiments at 800-2000 K and 0.1-0.3 MPa, and correlated the ignition delay times of pure methane, pure hydrogen, and their mixtures according to the following empirical formula:

$$
\tau=\tau_{\mathrm{CH}_{4}}^{(1-\zeta)} \tau_{\mathrm{H}_{2}}^{\zeta},
$$

where $\zeta$ is the amount-of-substance fraction of hydrogen in the fuel mixture; and $\tau_{\mathrm{CH}_{4}}$ and $\tau_{\mathrm{H}_{2}}$ are the ignition delay times of methane and hydrogen, respectively. Cheng and Oppenheimer's work on the ignition of methane/hydrogen mixtures was conducted at equivalence ratios below 1.0. Recently, Herzler and Naumann [14] investigated the ignition delay times of methane/ethane/hydrogen mixtures, which represented typical products of the gasification of biomass or coal, at $900-1800 \mathrm{~K}$ and $0.1,0.4$, or $1.6 \mathrm{MPa}$ in a high pressure shock tube. The relationship of the ignition delay to both the reference gas and a $40 \%$ hydrogen $/ 60 \%$ reference gas mixture were presented, and they suggested that none of the available mechanisms can reproduce the observed reduction in the activation energy for pure hydrogen and $80 \%$ hydrogen $/ 20 \%$ reference gas at low temperature when the pressure is $>0.4 \mathrm{MPa}$. Ignition delay times for mixtures with hydrogen amount-of-substance fractions $<40 \%$ and an equivalence ratio $>1$ were not reported by Herzler and Naumann. To the best of our knowledge, only few studies on ignition delay for methane/hydrogen mixtures have been reported [10-14], and the models are not optimal for prediction of the ignition delay time. Ignition delay data for methane/hydrogen mixtures, and in particular methane rich mixtures, are very important for modification of the model of methane/hydrogen oxidation.

In the present study, ignition delay and chemical kinetic analysis was conducted for homogeneous methane/ hydrogen/oxygen mixtures with hydrogen amount-of-substance fractions of $0 \%, 5 \%, 10 \%$ and $20 \%$. The fuel mixtures were diluted with nitrogen gas so that the nitrogen amount-ofsubstance fraction was $95 \%$. The temperature ranged from 1422 to $1877 \mathrm{~K}$, the pressure was $0.4 \mathrm{MPa}$, and the equivalence ratio was 2.0 behind the reflected shock wave. The data obtained are important for understanding the ignition mechanism of methane/hydrogen fuel in methane rich conditions.

\section{Experimental}

\subsection{Experimental setup}

The experiments were carried out in a shock tube facility (Figure 1) with a cross section of $130 \mathrm{~mm} \times 80 \mathrm{~mm}$. The driver section ( $2 \mathrm{~m}$ long) and the driven section (6.3 $\mathrm{m}$ long) were separated by a double diaphragm pump containing two polyvinyl chloride films $(0.07 \mathrm{~mm}$ thick). The shock tube was evacuated to a pressure of $<1 \times 10^{-3}$ torr by a Roots pump (ZJP-150, Chengdu Rankuum Machinery Ltd., Chengdu, China) before each experiment. Gas mixtures were prepared in a stainless steel storage cylinder over $12 \mathrm{~h}$. The shock speed was measured by four piezoelectric pressure gauges (113B26, PCB Piezotronics, Buffalo, NY) and three time interval counters (PM6690, Fluke, Everett, WA). The typical shock speed attenuation was $1.5 \%-3 \%$ per meter. The temperature and pressure behind the reflected shock wave were calculated from the measured incident shock speed and the speed attenuation using one-dimensional shock relations and NASA's thermodynamic database [15]. The experimental temperature $\left(T_{5}\right)$ uncertainty was calculated at about $18 \mathrm{~K}$ using a standard error analysis procedure based on the uncertainty in the measured incident shock velocities and the non-ideal shock reflection from the interactions 


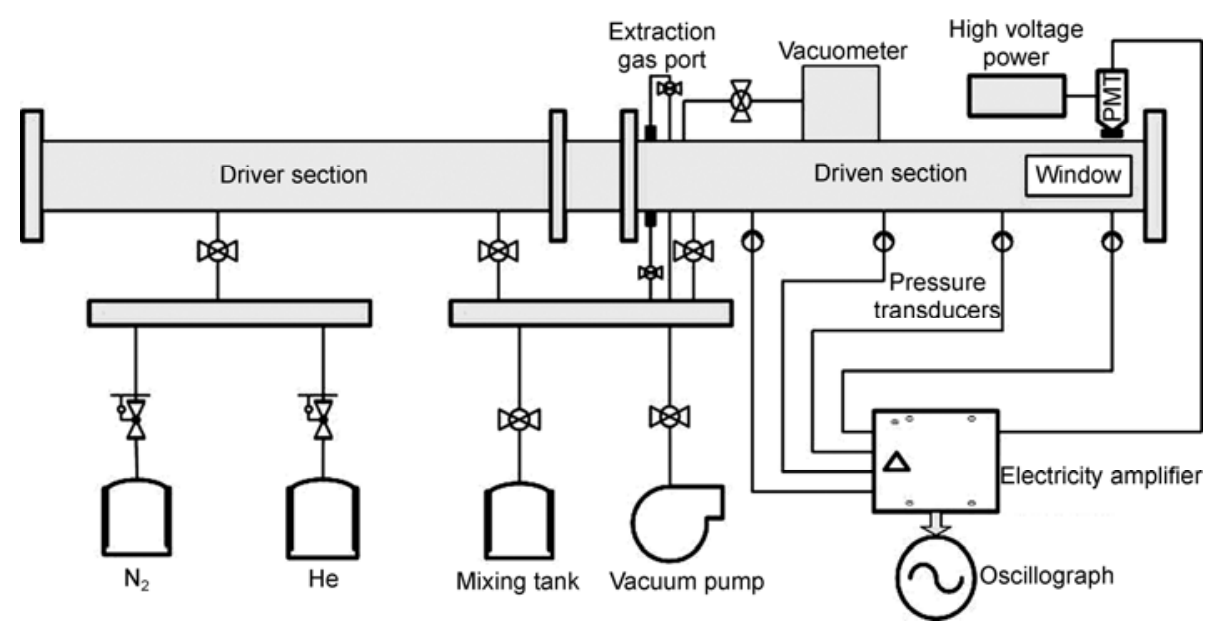

Figure 1 Experimental setup.

between the shock wave and boundary layer [16]. The purities of the methane, hydrogen, oxygen, nitrogen, and helium used in this study were higher than $99.995 \%$, 99.999\%, $99.995 \%, 99.995 \%$ and $99.999 \%$, respectively.

The pressure profile was obtained by a piezoelectric gauge (113B03, PCB Piezotronics) located at distance of $50 \mathrm{~mm}$ from the enwall. The HO- emission at $307 \mathrm{~nm}$ was acquired by a narrow band pass filter with a full width at half maximum measurement of $10 \mathrm{~nm}$ (UG-5, Schott, Elmsford, NY) and a photomultiplier (CR131, Hamamatsu Photonics, Hamamatsu, Japan). The ignition delay time was determined from the pressure profile and $\mathrm{HO} \cdot$ emission signal.

\subsection{Results and data analysis}

The ignition delay time of methane is relatively long compared to other fuels because of its high autoignition temperature. To ensure the accuracy of the experimental results, the effective experimental time must be longer than the ignition delay time. The interface conditions were optimized by tuning the thermodynamic properties of the driver gas, which was a mixture of nitrogen and helium, so that a second reflected shock wave was not generated when the first reflected shock wave interacted with the contacted face. For an ideal shock reflection, the conditions in the experimental region remain unaffected until the arrival of the rarefaction wave. In the present study, the interface conditions in the lower temperature experiments were tuned to obtain a longer ignition delay time.

The ignition delay times of the methane/hydrogen mixtures with hydrogen amount-of-substance fractions of $0 \%$, $5 \%, 10 \%$, and $20 \%$ were determined. The methane/oxygen/ hydrogen mixture was diluted with nitrogen gas $(95 \%$ in amount-of-substance fraction). The compositions of the gas mixtures used in the present study are presented in Table 1. The conditions for the reflected shockwave were as follows: temperature, 1422-1877 K; pressure, $0.4 \mathrm{MPa}$; and equivalence ratio, 2.0. A typical pressure (black solid line) and
Table 1 Compositions of the fuel mixtures used in this study

\begin{tabular}{cccccc}
\hline No. & \multicolumn{1}{c}{ Mixtures } & $\mathrm{XCH}_{4}(\%)$ & $\mathrm{XH}_{2}(\%)$ & $\mathrm{XO}_{2}(\%)$ & $\mathrm{XN}_{2}(\%)$ \\
\hline 1 & $100 \% \mathrm{CH}_{4}$ & 2.500 & 0.000 & 2.500 & 95.000 \\
2 & $95 \% \mathrm{CH}_{4} / 5 \% \mathrm{H}_{2}$ & 2.423 & 0.128 & 2.449 & 95.000 \\
3 & $90 \% \mathrm{CH}_{4} / 10 \% \mathrm{H}_{2}$ & 2.338 & 0.259 & 2.403 & 95.000 \\
4 & $80 \% \mathrm{CH}_{4} / 20 \% \mathrm{H}_{2}$ & 2.162 & 0.541 & 2.297 & 95.000 \\
\hline
\end{tabular}

-OH emission (magenta dash line) profile is shown in Figure 2. The pressure initially increased in two stages because of the arrival of incident and reflected shock waves at the test position, and then remained constant for about $0.8 \mathrm{~ms}$. Following this, a slow increase in the pressure occurred because of heat release from the ignition of the mixtures. The $\mathrm{HO} \cdot$ concentration peaked at $1.6 \mathrm{~ms}$, which corresponded to initiation of the main ignition. In this study, the ignition delay time was defined as the interval between the arrival of the reflected shock wave and the initiation of the main ignition, that is, the maximum HO- emission. The ignition delay times obtained in this manner agreed with the calculated

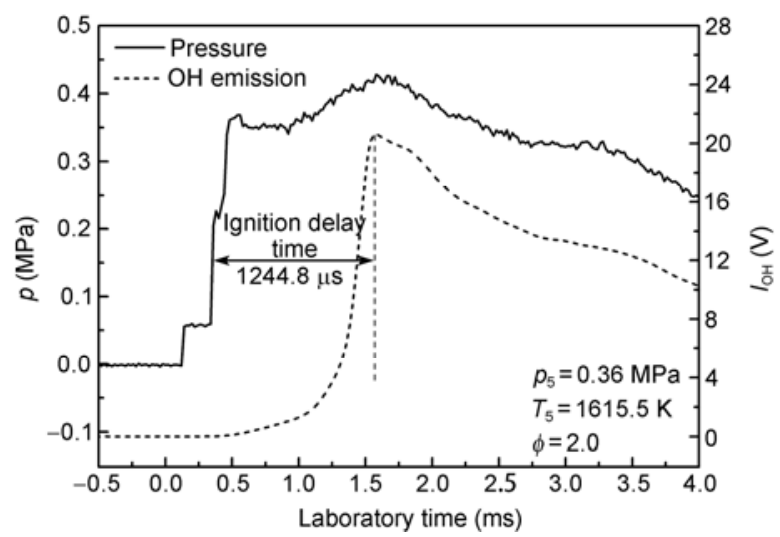

Figure 2 Typical pressure and $\mathrm{HO}$ - emission profile indicating the ignition delay time for a $95 \%$ methane $/ 5 \%$ hydrogen fuel mixture at $T_{5}=1615.5 \mathrm{~K}$ and $p_{5}=0.4 \mathrm{MPa}$. 
values presented in [14].

A comparison among the experimental and calculated (GRI-Mech 3.0 [17]) ignition delay times from this study and those of Petersen et al. [18], Wang et al. [19] and Hughes et al. [20] is shown in Figure 3. The predicted values from these mechanisms agree well with the experimental values for pure methane. For the ignition delay times of methane, the experimental results from the present study are about 4.5 times longer than those obtained by Herzler et al. using $92 \%$ methane and $8 \%$ ethane [14]. However, addition of ethane reduces the ignition delay time of methane. The activation energy for the present study was calculated at $53.4 \pm 0.35 \mathrm{kcal} / \mathrm{mol}$ using a multiple linear regression. A comparison of this with the activation energies from other studies [10,21-25] (Table 2) shows that the activation energy obtained here is slightly higher. This discrepancy may be attributed to differences in the experimental setup, experimental conditions, and dilution components among the studies. The global activation energy of pure methane was constant, and was characteristic of a hydrocarbon fuel.

The ignition delay time data for pure methane from the present study and previous studies were fit by multiple linear regression using the following Arrhenius-type equation based on the pressure, equivalence ratio, and amount-ofsubstance fraction of oxygen:

$\tau_{\text {ign }}=3.4734 \times 10^{-4} p^{-0.788} \phi^{0.255} X_{\mathrm{O}_{2}}^{-0.871} \exp \left(\frac{47.312(\mathrm{cal} / \mathrm{mol})}{R T}\right)$,

where $\tau_{\text {ign }}$ is the ignition delay time in $\mu \mathrm{s}, p$ is the pressure in $\mathrm{MPa}, \phi$ is the equivalence ratio, $X_{\mathrm{O}_{2}}$ is the amount-ofsubstance fraction of oxygen, $T$ is the temperature in $\mathrm{K}$, and $R$ is the universal gas constant in cal $(\mathrm{K} \mathrm{mol})$. The data fit this equation from 1007-2043 K, 0.54-48.1 MPa, and at equivalence ratios from $0.2-5.0$ with a multiple coefficient of determination, $r^{2}$, of 0.968 . The Arrhenius-type expression

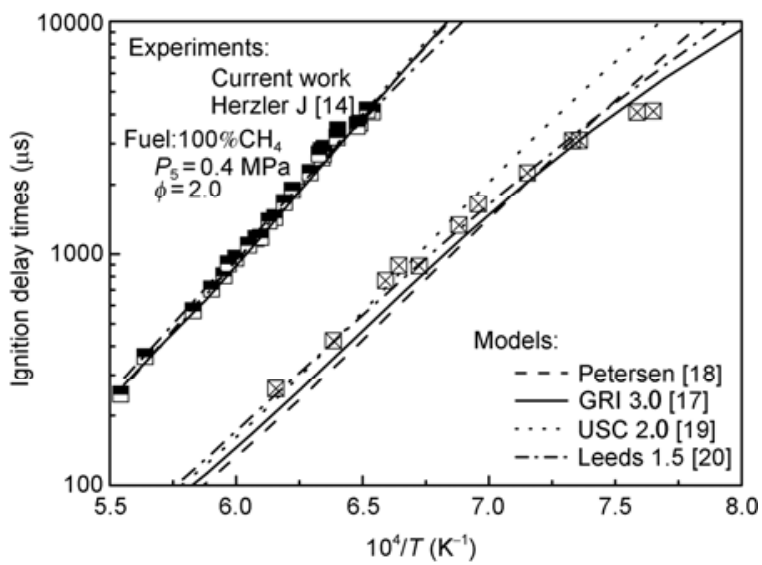

Figure 3 Comparison among the experimental and calculated (GRIMech 3.0 [17]) ignition delay times from this study (solid lines) and those of Petersen et al. [18] (dashed line), Wang et al. [19] (dotted line), and Hughes et al. [20] (dash/dotted line).
Table 2 Comparison among the results from the present work and previous studies

\begin{tabular}{|c|c|c|}
\hline Source & Experimental conditions & $\begin{array}{l}\text { Activation energy } \\
(\mathrm{kcal} / \mathrm{mol})\end{array}$ \\
\hline Current work & $\begin{array}{l}T_{5}=1400 \mathrm{~K}-1850 \mathrm{~K} \\
p_{5}=0.4 \mathrm{M} \mathrm{Pa} \\
\phi=2.0 \\
\mathrm{Ar}=95 \%\end{array}$ & 53.4 \\
\hline Grillo and Slack [21] & $\begin{array}{l}T_{5}=1649-2150 \mathrm{~K} \\
p_{5}=0.1-0.6 \mathrm{M} \mathrm{Pa} \\
\phi=1.0,2.0 \\
\mathrm{Ar}=79 \%-96 \%\end{array}$ & 52.3 \\
\hline Seery and Bowman [22] & $\begin{array}{l}T_{5}=1350-1900 \mathrm{~K} \\
p_{5}=0.15-0.4 \\
\phi=0.2-5.0 \\
\mathrm{Ar}=53.4 \%-78.4 \%\end{array}$ & 51.4 \\
\hline Petersen et al. [23-25] & $\begin{array}{l}T_{5}=1410-2040 \mathrm{~K} \\
p_{5}=0.9-48.0 \mathrm{MPa} \\
\phi=0.5-4.0 \\
\mathrm{Ar}=89 \%-99 \%, \mathrm{~N}_{2}=97.46 \%\end{array}$ & 51.8 \\
\hline Lifshitz et al. [10] & $\begin{array}{l}T_{5}=1500-2100 \mathrm{~K} \\
p_{5}=0.2-1.0 \mathrm{MPa} \\
\phi=0.5-2.0 \\
\mathrm{Ar}=89 \%-97 \%\end{array}$ & 46.5 \\
\hline
\end{tabular}

(Equation (2)) indicates that there is a negative correlation between the ignition delay time of the methane and the pressure and the amount-of-substance fraction of oxygen. Consequently, the ignition delay time will decrease as the pressure and amount-of-substance fraction of oxygen increase. However, there is a positive correlation between the equivalence ratio and the ignition delay time, which means the delay time will increase as the equivalence ratio increases. In the present study, the dependence of the ignition delay time on the equivalence ratio is much smaller than that on the pressure or amount-of-substance fraction of oxygen, which means the effect of the equivalence ratio on the ignition delay time is relatively weak. This result is in agreement with the results reported by Seery and Bowman [22]. The pressure dependence of $p^{-0.788}$ was used to plot all the data with the average pressure $(0.4 \mathrm{MPa})$ used in this study. The following pressure correlation was obtained:

$$
\tau_{\text {ign }, 0.4 \mathrm{MPa}}=\tau_{\text {ign }}\left(\frac{0.4}{p}\right)^{-0.788} .
$$

Figure 4 shows a comparison between experimental data and the calculated data obtained using the pressure dependence $p^{-0.788}$ and eq. (2). The slight disagreement of the ignition delay times can be attributed to different experimental conditions, such as pressures, temperatures, equivalence ratio and concentrations, and the definition of ignition delay.

The experimental conditions and measured ignition delay times are listed in Table 3 and presented in Figure 5. Hydrogen addition reduced the ignition delay times of the methane/hydrogen mixtures. The four mixtures had similar ignition delay times at $>1725 \mathrm{~K}$, which suggests that the 


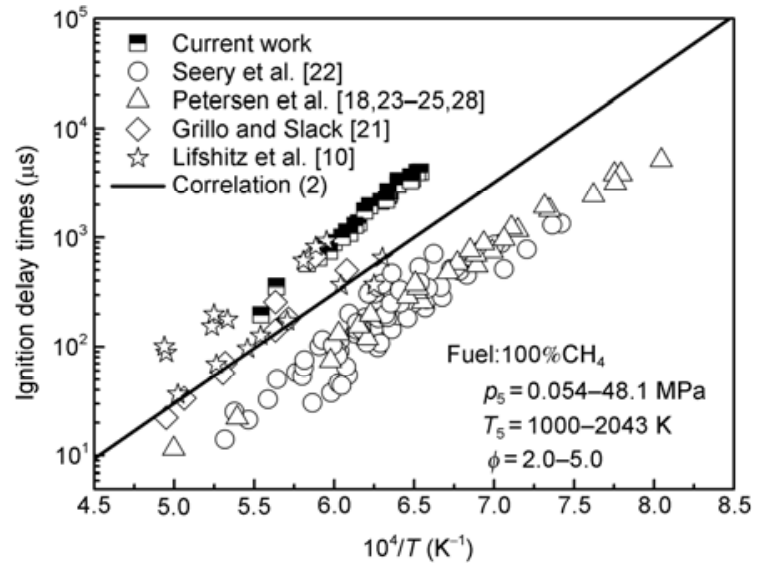

Figure 4 Comparison between the results calculated using eq. (2) and previous literature results for the ignition delay time with pressure, equivalence ratio, amount-of-substance fraction of oxygen and reflected shock temperature using a pressure dependence of $p^{-0.788}$. effect of hydrogen addition on ignition in the methane/hydrogen reactive system is weak at high temperatures. By contrast, the ignition delay time decreased substantially as the hydrogen amount-of-substance fraction increased at $<1725 \mathrm{~K}$, and the effect of hydrogen addition on the ignition delay was more pronounced as the temperature decreased. Specifically, at $1500 \mathrm{~K}$, for the $20 \%$ hydrogen $/ 80 \%$ methane mixture, the ignition delay time was reduced by a factor of three compared with that of pure methane. A reduction of the global activation energy was observed as the hydrogen amount-of-substance fraction increased. However, for each mixture in this study, the global activation energy did not change substantially because the methane chemistry dominated the reaction system under the current conditions. This is typical of hydrocarbon systems. The activation energies of the four fuels with hydrogen amount-of-substance fractions of $0,5 \%, 10 \%$, and $20 \%$ were $53.4,50.5,46.6$, and

Table 3 Experimental conditions and ignition delay times measured in the present study

\begin{tabular}{|c|c|c|c|c|c|c|c|}
\hline Mixtures & $T(\mathrm{~K})$ & $p(\mathrm{MPa})$ & $\tau_{\mathrm{ign}}(\mu \mathrm{s})$ & Mixtures & $T(\mathrm{~K})$ & $p(\mathrm{MPa})$ & $\tau_{\text {ign }}(\mu s)$ \\
\hline \multirow[t]{13}{*}{$100 \% \mathrm{CH}_{4}$} & 1804 & 0.36 & 247 & \multirow[t]{13}{*}{$100 \% \mathrm{CH}_{4}$} & 1589 & 0.38 & 2248 \\
\hline & 1773 & 0.4 & 361 & & 1580 & 0.35 & 2698 \\
\hline & 1715 & 0.36 & 569 & & 1578 & 0.37 & 2793 \\
\hline & 1694 & 0.39 & 705 & & 1577 & 0.37 & 2608 \\
\hline & 1680 & 0.37 & 805 & & 1576 & 0.36 & 2705 \\
\hline & 1675 & 0.38 & 907 & & 1575 & 0.36 & 2856 \\
\hline & 1667 & 0.36 & 957 & & 1562 & 0.38 & 3188 \\
\hline & 1645 & 0.38 & 1165 & & 1543 & 0.4 & 3620 \\
\hline & 1640 & 0.36 & 1175 & & 1543 & 0.37 & 3558 \\
\hline & 1631 & 0.36 & 1385 & & 1541 & 0.37 & 3666 \\
\hline & 1625 & 0.37 & 1433 & & 1534 & 0.38 & 4170 \\
\hline & 1615 & 0.41 & 1668 & & 1529 & 0.39 & 4096 \\
\hline & 1607 & 0.41 & 1885 & & & & \\
\hline \multirow[t]{11}{*}{$95 \% \mathrm{CH}_{4}$} & 1815 & 0.35 & 203 & \multirow[t]{11}{*}{$95 \% \mathrm{CH}_{4}$} & 1623 & 0.37 & 1077 \\
\hline & 1798 & 0.36 & 192 & & 1616 & 0.38 & 1245 \\
\hline & 1786 & 0.37 & 318 & & 1592 & 0.38 & 1684 \\
\hline & 1724 & 0.37 & 454 & & 1577 & 0.37 & 1880 \\
\hline & 1716 & 0.35 & 498 & & 1572 & 0.37 & 1922 \\
\hline & 1698 & 0.37 & 537 & & 1553 & 0.4 & 2694 \\
\hline & 1693 & 0.37 & 727 & & 1545 & 0.37 & 2868 \\
\hline & 1687 & 0.36 & 760 & & 1538 & 0.38 & 3199 \\
\hline & 1675 & 0.38 & 696 & & 1523 & 0.38 & 3289 \\
\hline & 1657 & 0.37 & 824 & & 1518 & 0.37 & 3579 \\
\hline & 1655 & 0.38 & 752 & & 1505 & 0.38 & 3960 \\
\hline \multirow[t]{7}{*}{$90 \% \mathrm{CH}_{4}$} & 1877 & 0.31 & 122 & \multirow[t]{7}{*}{$90 \% \mathrm{CH}_{4}$} & 1534 & 0.36 & 2254 \\
\hline & 1763 & 0.33 & 287 & & 1527 & 0.39 & 2246 \\
\hline & 1686 & 0.33 & 542 & & 1515 & 0.36 & 2776 \\
\hline & 1650 & 0.34 & 742 & & 1497 & 0.35 & 3126 \\
\hline & 1629 & 0.35 & 876 & & 1494 & 0.36 & 3026 \\
\hline & 1613 & 0.31 & 994 & & 1490 & 0.39 & 3316 \\
\hline & 1598 & 0.3 & 1164 & & 1479 & 0.37 & 3496 \\
\hline \multirow[t]{7}{*}{$80 \% \mathrm{CH}_{4}$} & 1831 & 0.32 & 210 & \multirow[t]{7}{*}{$80 \% \mathrm{CH}_{4}$} & 1577 & 0.39 & 949 \\
\hline & 1829 & 0.32 & 187 & & 1571 & 0.37 & 996 \\
\hline & 1774 & 0.36 & 234 & & 1532 & 0.35 & 1618 \\
\hline & 1717 & 0.35 & 377 & & 1476 & 0.36 & 2253 \\
\hline & 1677 & 0.37 & 457 & & 1426 & 0.37 & 3014 \\
\hline & 1644 & 0.37 & 572 & & 1422 & 0.35 & 3194 \\
\hline & 1638 & 0.36 & 602 & & & & \\
\hline
\end{tabular}




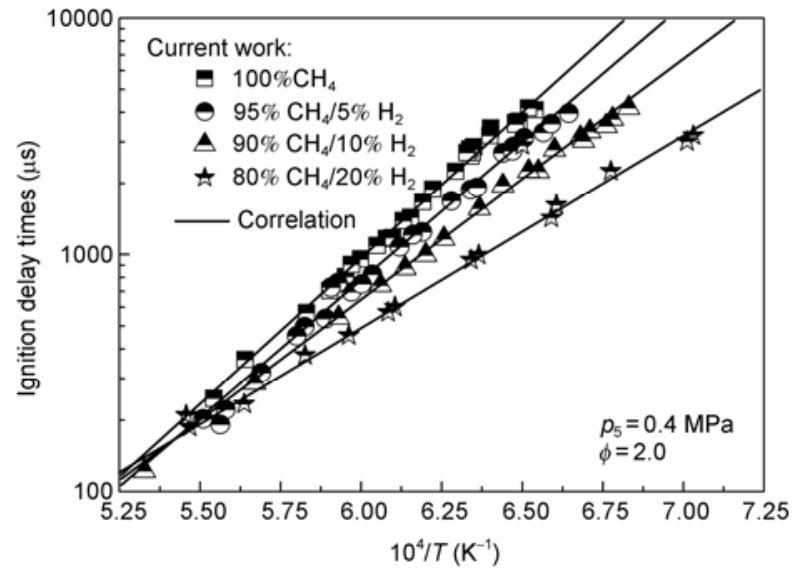

Figure 5 Effect of hydrogen addition (hydrogen amount-of-substance fractions $=0 \%, 5 \%, 10 \%$, and $20 \%$ ) on the ignition delay time of the methane/hydrogen system.

$41.7 \mathrm{kcal} / \mathrm{mol}$, respectively. The activation energies derived from eq. (1) proposed by Cheng and Oppenheim [13] for the same methane/hydrogen mixtures with hydrogen amountof-substance fractions of $0,5 \%, 10 \%$, and $20 \%$ were 53.4 , $51.6,49.8$, and $46.2 \mathrm{kcal} / \mathrm{mol}$, respectively. A comparison of the experimental and calculated activation energies reveals some differences. Therefore, further investigation is necessary for the Arrhenius-type expression of the ignition delay time for methane/hydrogen mixtures.

\section{Chemical kinetic analysis}

\subsection{Kinetic model}

In this study, a modified model including 353 elementary reactions and 53 species was proposed based on GRI-Mech 3.0 [17]. The main body of the modified model is identical to that of GRI-Mech 3.0. Four elementary reactions, which are the key to the ignition mechanism of the methane/hydrogen reactive system, were improved. Because the experimental temperatures in the present study ranged from $1422-1877 \mathrm{~K}$, the alkylperoxy chemistry, including the formation and consumption of $\mathrm{CH}_{3} \mathrm{O}_{2}$, at low temperatures proposed by Petersen et al. [25] was ignored. For the ignition delay of methane/oxygen/argon mixtures or methane/ oxygen/nitrogen mixtures, the modified model based on GRI-Mech 3.0 can reproduce experimental results over a wide range of conditions. The elementary reaction rate coefficient $k_{i}$ is calculated using the following formula:

$$
k_{i}=A T^{\beta} \exp (E / R T)
$$

where $k_{i}$ is the $i$ th elementary reaction rate coefficient, $A$ is a constant, $\beta$ is the temperature coefficient, $E$ is the activation energy $\mathrm{kJ} / \mathrm{mol}, T$ is the temperature in $\mathrm{K}$, and $R$ is the universal gas constant in cal/K mol.

The reactions for improvement were identified based on the results of preliminary sensitivity and reaction flow analysis. The $\mathrm{H} \cdot$ in the hydrogen ignition system was mainly scavenged through the following reaction:

$$
\mathrm{H} \cdot+\mathrm{O}_{2}+\mathrm{N}_{2} \rightarrow \mathrm{HO}_{2} \cdot+\mathrm{N}_{2}
$$

The rate for this reaction was replaced using the values proposed by Hughes et al. [20]. The $A, \beta, E$ values were 2.1 $\times 10^{18},-0.8,0.0 \mathrm{cal}$, respectively. The following reaction,

$$
\mathrm{H} \cdot+\mathrm{CH}_{4} \rightarrow \mathrm{H}_{3} \mathrm{C} \cdot+\mathrm{H}_{2}
$$

is key to the methane/hydrogen reactive system because it involves both methane and hydrogen. A review of the literature related to the rate of reaction R53 shows that the experimental or theoretical data reported by different authors varies by a factor of three, which could account for a change of $20-30 \%$ in the calculated ignition delay time. The rate of reaction R53 was obtained from GRI-Mech 3.0 [17] and Hughes et al. [20], the $A, \beta, E$ were $1.32 \times 10^{4}, 3.0,10840 \mathrm{cal}$, respectively. Reaction $\mathrm{R} 84$, which leads to production of active hydrogen radical was also improved.

$$
\mathrm{HO} \cdot+\mathrm{H}_{2} \rightarrow \mathrm{H} \cdot+\mathrm{H}_{2} \mathrm{O}
$$

was improved. The rate for this reaction was adopted from Huang et al. [12], and the $A, \beta, E$ were $1.81 \times 10^{9}, 1.2,4707$ cal, respectively. The rate of the third-order reaction $\mathrm{R} 33$ was adopted from the work of Petersen et al. [18], and the values of $A, \beta, E$ were $1.475 \times 10^{12}, 0.6,0.0$ cal, respectively.

$$
\mathrm{H} \cdot+\mathrm{O}_{2}+\mathrm{M} \rightarrow \mathrm{HO}_{2} \cdot+\mathrm{M}
$$

Reaction R33 is the main consumption mechanism for $\mathrm{H} \cdot$.

Numerical simulation of the ignition delay behind the reflected shock waves was performed using a zero-dimensional model with constrained volume and adiabatic boundary. This model has been used to calculate ignition delay time in many studies. For consistency with the basic mechanism, the thermodynamic properties of the reactants and species properties were mostly taken from the NASA's database [15]. To allow for comparison of the results, the same definition was used for the calculated ignition delay as in the experimental study. The steady state mass, species properties, and energy conservation equations were carried out by using CHEMKIN II (Reaction Design, San Diego, CA) with Senkin code. A gas-phase interpreter to process the chemical reaction mechanism was built in the CHEMKIN II.

\subsection{Analysis and discussion}

Figure 6 presents the results for the ignition delay times calculated using the modified model and GRI-Mech 3.0 together with the experimental data from the present study. The ignition delay times of the methane/hydrogen fuel mixtures decreased slightly with hydrogen addition, and this 
effect was slightly weaker at lower temperatures with a hydrogen amount-of-substance fraction $<10 \%$. Both GRI-Mech 3.0 and the modified mechanism predicted accurate ignition delay times for the methane/hydrogen/oxygen/nitrogen mixtures with hydrogen amount-of-substance fractions $<10 \%$. This is because methane chemistry dominated in the reactive system, especially for mixtures with low hydrogen amountof-substance fractions, and changes in the rates of reactions R84, R36, R53, and R33 could not substantially influence the ignition and oxidation chemistry of the methane/hydrogen mixtures where the methane reaction mechanism is dominate. However, these reaction rate changes led to a slight discrepancy between the modified mechanism and GRIMech 3.0 in calculating the ignition delay time. This is consistent with the report of Fotache et al. [26], which detailed that the much stronger effect of hydrogen on the methane/ air ignition in a diffusive system was because of the separation of hydrogen from other species as a result of its high diffusivity. However, the scavenging effect of methane on $\mathrm{H} \cdot$ can be much stronger via reaction R53 in a homogeneous reactor, which results in the reduced effect of hydrogen addition on the reaction system. Fotache et al. [26] suggested that the ignition was effective through radical rather than thermal explosion for methane/air mixtures with a high hydrogen amount-of-substance fraction. To gain further insight into this, Huang et al. [12] conducted an investigation by removing the reaction heat of all the elementary reactions from the energy equation. Their results showed that the ignition delay times for both methane and methane/hydrogen mixtures increased, and the differences of the ignition delay times among these mixtures did not change significantly. The thermal feedback, which is important to the overall reaction rate, has a similar contribution to the oxidation of methane and hydrogen.

GRI-Mech 3.0 largely over predicts the ignition delay time of the methane/hydrogen mixtures when the hydrogen amount-of-substance fraction is $>10 \%$, and particularly when

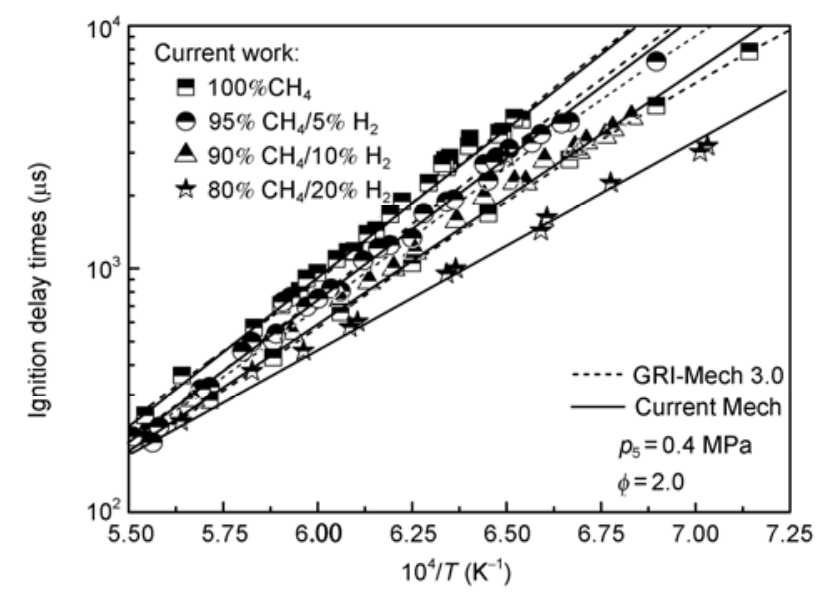

Figure 6 Calculated ignition delay times of methane/hydrogen/oxygen/ nitrogen mixtures with hydrogen amount-of-substance fractions ranging from $0 \%$ to $20 \%$. the temperature is $<1500 \mathrm{~K}$. Specifically, for the $20 \%$ hydrogen/80\% methane mixture, the predicted values are about two times those from the experimental data. However, the modified mechanism from the present study can accurately reproduce the ignition delay time for conditions with relative high hydrogen amount-of-substance fractions. In particular, the effect of hydrogen addition on the ignition delay time is obvious at low temperature, because the hydrogen subsystem plays an important role on in the methane/hydrogen reactive system at low temperature. The changes of the reaction rate for the four elementary reactions mentioned above led to a reduction in the calculated ignition delay time, and this was particularly apparent for the reaction rate of $\mathrm{R} 53$. However, for the hydrogen subsystem, GRI-Mech 3.0 has not been optimized under low temperature conditions, which leads to the different results when predicting the ignition delay times of the methane/ hydrogen mixtures.

To explain the contribution of the rates of the elementary reactions relative to the total reaction rate, a normalized sensitivity analysis was conducted to investigate the effect of the main elementary reactions on methane/hydrogen ignition with hydrogen addition at $1400 \mathrm{~K}$ and $1800 \mathrm{~K}$. The normalized sensitivity analysis was calculated with the following expression:

$$
S_{k_{i}} \approx \frac{\tau\left(2 k_{i}\right)-\tau\left(0.5 k_{i}\right)}{2 k_{i}-0.5 k_{i}} \frac{k_{i}}{\tau\left(k_{i}\right)}=\frac{\tau\left(2 k_{i}\right)-\tau\left(0.5 k_{i}\right)}{1.5 \tau\left(k_{i}\right)} .
$$

Figure 7 shows the sensitivity analysis of the methane/ hydrogen/oxygen/nitrogen mixtures with hydrogen amountof-substance fractions ranging from $0 \%$ to $20 \%$. These results suggest that at $1400 \mathrm{~K}$, the chain branching reaction $\mathrm{R} 38$ and the chain propagation reactions R119 and R84 advance the overall reaction rate and promote the ignition process of the methane/hydrogen system.

$$
\begin{aligned}
\mathrm{H} \cdot+\mathrm{O}_{2} & \rightarrow \mathrm{O} \cdot+\mathrm{HO} \\
\mathrm{HO}_{2} \cdot+\mathrm{H}_{3} \mathrm{C} & \rightarrow \mathrm{HO} \cdot+\mathrm{CH}_{3} \mathrm{O} \\
\mathrm{HO} \cdot+\mathrm{H}_{2} & \rightarrow \mathrm{H} \cdot+\mathrm{H}_{2} \mathrm{O}
\end{aligned}
$$

The sensitivity factors of R38 and R84 increase with hydrogen addition, which will lead to further promotion of the ignition process. The $\mathrm{H} \cdot$ scavenging reaction $\mathrm{R} 53$, the recombination of $\mathrm{H}_{3} \mathrm{C}$ - in $\mathrm{R} 158$, and the chain propagation reaction $\mathrm{R} 98$ reduce the overall reaction rate and inhibit the ignition process of the methane/hydrogen system.

$$
\begin{gathered}
\mathrm{H} \cdot+\mathrm{CH}_{4} \rightarrow \mathrm{H}_{3} \mathrm{C} \cdot+\mathrm{H}_{2} \\
2 \mathrm{H}_{3} \mathrm{C} \cdot(+\mathrm{M}) \rightarrow \mathrm{C}_{2} \mathrm{H}_{6}(+\mathrm{M}) \\
\mathrm{HO} \cdot+\mathrm{CH}_{4} \rightarrow \mathrm{H}_{3} \mathrm{C} \cdot+\mathrm{H}_{2} \mathrm{O}
\end{gathered}
$$

The sensitivity factors of reactions R98 and R158 increase with hydrogen addition, which will increase the inhibition effect on the ignition process. The production rate of $\mathrm{H} \cdot$ through R84 increases as the hydrogen amount-of- 

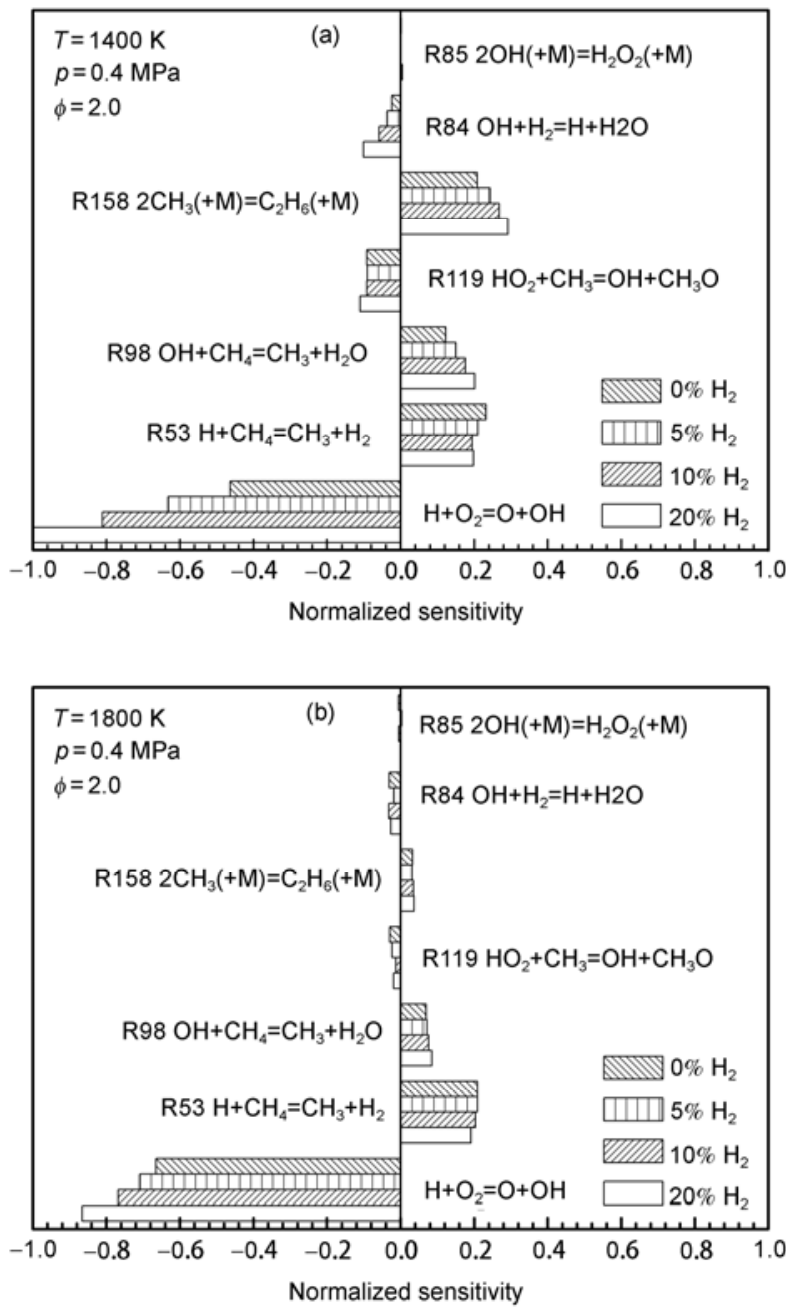

Figure 7 Normalized sensitivity analysis of the ignition delay time with hydrogen addition at (a) 1400 and (b) $1800 \mathrm{~K}$.

substance fraction increases. However, HO- concentrations increase rapidly through $\mathrm{R} 38$, which will move reaction R98 to the right. Reaction R53 is usually considered as the main $\mathrm{H} \cdot$ consumption step in the methane/hydrogen system $[24,25]$. In this study, reaction R53 enhances ignition, which is different to the results reported by Huang et al. [12]. The sensitivity factor of reaction R53 decreased with hydrogen addition, and this reduced the enhancement of ignition. This can be explained as follows. Firstly, with hydrogen addition reaction R53 will shift in the reverse direction, and decrease the reaction rate in the forward direction. Secondly, as hydrogen is added it will replace some of the methane in the mixture, which will decrease the methane concentration and increase the reverse reaction rate of R53. Reaction R98 is the main reaction in competition to R53 for methane. Reaction R98 showed a reverse trend to reaction R53 for the sensitivity of ignition delay of methane/hydrogen fuels to hydrogen addition. Reaction R119 is the main reaction in competition to $\mathrm{R} 158$ for $\mathrm{H}_{3} \mathrm{C}$, and the sensitivity factors of these reactions have opposing signs. The sensitivity factor of reaction R158 increases with hydrogen addition. Although the $\mathrm{HO}_{2}$ concentration is increased by reaction R119 with hydrogen addition, the chain termination efficiency of reaction R158 strongly affects reaction R119. Therefore, only a small change occurs in the normalized sensitivity of reaction R119 with hydrogen addition. Furthermore, HO- is actively generated though reaction R119, and HO- is one of the key species in the oxidation of methane. The sensitivity factor of reaction R84 increases with hydrogen addition, which will lead to an increase in the production rate of $\mathrm{H}$. However, $\mathrm{H} \cdot$ is known to be more active than $\mathrm{HO}$, which will increase the rate of the chain branching reaction R38 and the HO- concentration rapidly, and this will promote the ignition process of the methane/hydrogen mixtures.

At $1800 \mathrm{~K}$, the sensitivity factors of the main elementary reaction in the methane/hydrogen system were reduced. In particular, reactions R158 and R119 were greatly enhanced. The combination reaction of the $\mathrm{H}_{3} \mathrm{C} \cdot$ is an important chain termination reaction at high temperature. Because the temperature dominates in the methane/hydrogen system under high temperature conditions, the effect of hydrogen addition on the sensitivity factors of the elementary reactions was weak. This makes the ignition delay times for four fuels similar at high temperature. Because of the branching efficiency of reaction R38, the sensitivity factor of R84 was reduced and the formation rate of $\mathrm{H} \cdot$ decreased, which led to a slight increase in the effect of hydrogen addition on the ignition for methane/hydrogen system and a negligible change in the ignition delay times. The sensitivity analysis at different temperatures suggests the rates of some of the elementary reactions are uncertain. Huang et al. [12] reported that the following third-order recombination reactions are the rate limiting steps:

$$
\begin{array}{cc}
\mathrm{H} \cdot+\mathrm{O}_{2}+\mathrm{M} \rightarrow \mathrm{HO}_{2} \cdot+\mathrm{M} & \mathrm{R} 33 \\
\mathrm{H} \cdot+\mathrm{O}_{2}+\mathrm{H}_{2} \mathrm{O} \rightarrow \mathrm{HO}_{2} \cdot+\mathrm{H}_{2} \mathrm{O} & \mathrm{R} 35 \\
\mathrm{H} \cdot+\mathrm{O}_{2}+\mathrm{N}_{2} \rightarrow \mathrm{HO}_{2} \cdot+\mathrm{N}_{2} & \mathrm{R} 36 \\
\mathrm{H} \cdot+\mathrm{O}_{2}+\mathrm{Ar} \rightarrow \mathrm{HO}_{2} \cdot+\mathrm{Ar} & \mathrm{R} 37
\end{array}
$$

This leads to a larger discrepancy in the ignition delay times predicted by the modified model and GRI-Mech 3.0 with high hydrogen amount-of-substance fractions at low temperature. The modified model in this study has only been improved using experimental data, and other fundamental combustion parameters such as the laminar flame speed and species concentration analysis have not been validated. Therefore, further experimental and theoretical studies, including of the key reaction rates, are necessary.

\section{Conclusions}

Experimental and numerical studies were conducted in a shock tube facility to evaluate the ignition delay times of methane/hydrogen/oxygen/nitrogen mixtures with hydrogen 
fractions of $0-20 \%$ at $1422-1877 \mathrm{~K}$ and $0.4 \mathrm{MPa}$ with an equivalence ratio of 2.0. The main conclusions are summarized below.

(1) An Arrhenius-type correlation based on pressure, equivalence ratio and the oxygen amount-of-substance fraction was obtained for pure methane. The reduction of the ignition delay time with hydrogen addition in the methane/ hydrogen system increased as the temperature decreased. At $1500 \mathrm{~K}$, the ignition delay time of the $80 \%$ methane $/ 20 \%$ hydrogen mixtures was reduced by a factor of three compared to that of pure methane. However, at $1750 \mathrm{~K}$, the effect of hydrogen addition on the reduction of the ignition delay was weak.

(2) A modified model basing on GRI-Mech 3.0 was developed and applied to simulate ignition of the methane/ hydrogen/oxygen/nitrogen mixtures behind reflected shock waves under the current experimental conditions. The experimental and calculated results agreed. Normalized sensitivity analysis of the ignition delay suggested that formation and consumption reactions of $\mathrm{H} \cdot$ were key factors in the ignition of the methane/hydrogen system. At $1400 \mathrm{~K}$, hydrogen was rapidly oxidized through the reaction $\mathrm{HO}+$ $\mathrm{H}_{2} \rightarrow \mathrm{H} \cdot+\mathrm{H}_{2} \mathrm{O}$ (R84), and this strongly promoted the chain branching reaction $\mathrm{H} \cdot+\mathrm{O}_{2} \rightarrow \mathrm{O} \cdot+\mathrm{HO} \cdot(\mathrm{R} 38)$. The sensitivity factors increased substantially with hydrogen addition, and the ignition delay time of the methane/hydrogen fuel mixtures decreased. Furthermore, since the rate of the reaction $\mathrm{H} \cdot+\mathrm{CH}_{4} \rightarrow \mathrm{H}_{3} \mathrm{C} \cdot+\mathrm{H}_{2}(\mathrm{R} 53)$ is reduced, the enhancement effect on the ignition becomes weak. At $1800 \mathrm{~K}$, the $\mathrm{H}_{3} \mathrm{C}$. dominate in the ignition mechanism of the methane/hydrogen mixture and the sensitivity factors for recombination of two $\mathrm{CH}_{3} \quad 2 \mathrm{H}_{3} \mathrm{C} \cdot(+\mathrm{M}) \rightarrow \mathrm{C}_{2} \mathrm{H}_{6}(+\mathrm{M}) \quad(\mathrm{R} 158), \quad \mathrm{HO}_{2} \cdot+\mathrm{H}_{3} \mathrm{C} \cdot \rightarrow \mathrm{HO} \cdot+$ $\mathrm{CH}_{3} \mathrm{O} \cdot(\mathrm{R} 119)$, and the chain termination reaction $\mathrm{HO} \cdot+$ $\mathrm{H}_{2} \rightarrow \mathrm{H} \cdot+\mathrm{H}_{2} \mathrm{O}(\mathrm{R} 84)$ are decreased. This reduces the enhancement effect on ignition of the methane/hydrogen system with hydrogen addition under high temperature conditions.

This work was supported by the National Basic Research Program of China (2007CB210006) and the National Natural Science Foundation of China (50876085 and 50821604).

1 Richards G A, McMillian M M, Gemmen R S, et al. Issues for low emission, fuel flexible power systems. Prog Energ Combust Sci, 2001, 27: 141-169

2 Hao J, Rice P A, Stern S A. Upgrading low quality natural gas with $\mathrm{H}_{2} \mathrm{~S}$ and $\mathrm{CO}_{2}$ selective polymer membranes Part I. Process design and economics of membrane stages without recycle streams. J Membrane Sci, 2002, 209: 117-206

3 Shrestha S O B, Karim G A. Hydrogen as an additive to methane for spark ignition engine applications. Int J Hydrogen Energ, 1999, 24: $577-586$

4 Gauducheau J L, Denet B, Searby G. A numerical study of lean $\mathrm{CH}_{4}-\mathrm{H}_{2}$-air premixed flames at high pressure. Combust Sci Technol,
137: 81-89

5 Dagaut P, Dayma G. Hydrogen enriched natural gas blend oxidation under high pressure conditions: Experimental and detailed chemical kinetic modeling. Int J Hydrogen Energ, 2006, 31: 505-515

6 Dagaut P, Nicolle A. Experimental and detailed kinetic modeling study of hydrogen enriched natural gas blend oxidation over extended temperature and equivalence ratio ranges. P Combust Inst, 2005, 30: 2631-2638

7 Konnov A A, Riemeijer R, de Goey L P H. Adiabatic laminar burning velocities of $\mathrm{CH}_{4} / \mathrm{H}_{2} /$ air flame at low pressure. Fuel, 2009, 89: 1392-1396

$8 \mathrm{Hu}$ E J, Huang Z H, He J J, et al. Experimental and numerical study on laminar burning characteristics of premixed methane/hydrogen/air flames. Int J Hydrogen Energ, 2009, 34: 4876-4888

$9 \mathrm{Hu}$ E J, Huang Z H, He J J, et al. Experimental and numerical study on lean premixed methane/hydrogen/air flames at elevated pressures and temperatures. Int J Hydrogen Energ, 2009, 34: 6951-6960

10 Lifshitz A, Scheller K, Burcat A. Shock tube investigation of ignition in methane oxygen argon mixtures. Combust Flame, 1971, 16: 311-321

11 Gersen S, Anikin N B, Mokhov A V, et al. Ignition properties of methane/hydrogen mixtures in a rapid compression machine. Int J Hydrogen Energ, 2008, 33: 1957-1964

12 Huang J, Bushe W K, Hill P G, et al. Experimental and kinetic study of shock initiated ignition in homogeneous methane-hydrogen-air mixtures at engine-relevant conditions. Int J Chem Kinet, 2006, 38: 221-233

13 Cheng R K, Oppenheim A K. Auto-ignition in methane hydrogen mixtures. Combust Flame, 1984, 58: 125-139

14 Herzler J, Naumann C. Shock tube study of the ignition of methaneethane-hydrogen mixtures with hydrogen contents from $0 \%$ to $100 \%$ at different pressures. P Combust Inst, 2009, 32: 213-220

15 Burcat A, McBride B, Rabinowitz M. 1990 ideal gas thermodynamic data for compounds used in combustion. Faculty of Aerospace Engineering, Technion, Haifa, NASA Lewis Research Center, Cleveland, Ohio, USA

16 Holman J P. Experimental Methods for Engineers. New York: McGraw-Hill, 1984

17 Smith G P, Golden D M, Frenklach M, et al. GRI-MECH 3.0, 1999, http://www. me.berkeley.edu/gri_mech/

18 Petersen E L, Kalitan D M, Simmons S, et al. Methane/propane oxidation at high pressures: Experimental and detailed chemical kinetic modeling. P Combust Inst, 2007, 31: 447-454

19 Wang H, You X, Joshi A V, et al. USC Mech Version II. High temperature combustion reaction model of $\mathrm{H} 2 / \mathrm{CO} / \mathrm{C} 1-\mathrm{C} 4$ compounds. 2007, http://ignis.usc.edu/USC Mech_II.htm

20 Hughes K J, Turányi T, Clague A, et al. Development and testing of a comprehensive chemical mechanism for the oxidation of methane. Int J Chem Kinet, 2001, 33: 513-538

21 Grillo A, Slack M W. Shock tube study of ignition delay times in methane/oxygen/nitrogen/argon mixtures. Combust Flame, 1976, 27: 377-381

22 Seery D J, Bowman C T. Experimental and analytical study of methane oxidation behind shock waves. Combust Flame, 1970, 14: 37-48

23 Petersen E L, Hall J M, Smith S D, et al. Ignition of lean methane-based fuel blends at gas turbine pressures. ASME, 2007, 129: 937-944

24 de Vries J, Petersen E L. Autoignition of methane-based fuel blends under gas turbine conditions. P Combust Inst, 2007, 31: 3163-3171

25 Petersen E L, Davidson D F, Hanson R K. Kinetics modeling of shock induced ignition in low dilution $\mathrm{CH}_{4} / \mathrm{O}_{2}$ mixtures at high pressures and intermediate temperatures. Combust Flame, 1999, 117: 272-290

26 Fotache C G, Kreutz T G, Law C K. Ignition of hydrogen-enriched methane by heated air. Combust Flame, 1997, 110: 429-440

$27 \mathrm{Ju} \mathrm{Y,} \mathrm{Niioka} \mathrm{T.} \mathrm{Extinction} \mathrm{of} \mathrm{a} \mathrm{diffusion} \mathrm{flame} \mathrm{in} \mathrm{supersonic} \mathrm{mixing}$ layer. Combust Flame, 1994, 102: 462-470

28 Petersen E L, Rohrig M, Davidson D F, et al. High pressure methane oxidation behind reflected shock waves. P Combust Inst, 1996, 21: 799-806

Open Access This article is distributed under the terms of the Creative Commons Attribution License which permits any use, distribution, and reproduction in any medium, provided the original author(s) and source are credited. 